M.G. Hennerici (ed.)

\section{Imaging in Stroke}

Remedica Publishing, 2003

216 pp.; USD 45.00

ISBN 1-9013-4625-0

The imaging revolution for neuroscience began in the 1970s and continues unabated today. The clinical neurosciences have benefited more than any other group from these advances and for those managing stroke the benefits have been perhaps even greater. Imaging has led us to improvements in classification of stroke and, ultimately, therapy. Hence, any volume dedicated to this topic has an immediate advantage and the expectation that it will be useful to a broad interest group is high. With Imaging in Stroke, edited by Hennerici, we were not disappointed. The volume is timely in that we are going through a period of enormous consolidation of our knowledge of various imaging techniques and this needs to be collated in an accessible way.

To do this, experts in the field have contributed to the areas of $\mathrm{CT}$, MR, ultrasound, PET and functional imaging techniques (PET and MR). In each of these areas the basic principles are outlined with all the key information expressed simply, often with the aid of helpful diagrams and images. For example, the chapter by Olav Jansen on CTA and MRA in stroke is particularly useful, with practical diagrams demonstrating arterial and venous changes in such conditions as venous sinus thrombosis and arterial dissection. Tobias Neumann-Haefelin and Michael Moseley have written a good overview of MRI in acute stroke with simple diagrams to explain the basic underlying principles of physics before moving on to clinical applications. Other chapters are equally good.

Prior to embarking on the imaging sections, de Freitas and Bogousslavsky provide an excellent review of stroke classifications, with a review of the well-recognised classifications of the Lausanne Stroke Registry, Oxfordshire Community Stroke Project and TOAST classifications. Since all of these acquire at least some imaging input, it is a useful prelude to the main event.

With its 8 chapters, the book is not overly large and my copy was a paperback, so I felt it could be easily transported to the Stroke Unit ward to show my junior colleagues. I felt that it would be of use to them as well as almost any other clinician who is involved in the management of stroke. I strongly recommend it to all.

G.A. Donnan, Melbourne

\section{KARGER}

Fax +4161306 1234 E-Mail karger@karger.ch www.karger.com
(C) 2004 S. Karger AG, Basel

1015-9770/04/0183-0268\$21.00/0

Accessible online at: www.karger.com/ced 